\title{
Potential Adult Medicaid Beneficiaries Under the Patient Protection and Affordable Care Act Compared With Current Adult Medicaid Beneficiaries
}

\author{
Tammy Chang, $M D, M P H, M S^{1-3}$ \\ Matthew Davis, MD, MAPP $P^{2-5}$ \\ 'Department of Family Medicine, Uni- \\ versity of Michigan Health System, Ann \\ Arbor, Michigan
}

${ }^{2}$ Robert Wood Johnson Foundation Clinical Scholars Program, University of Michigan, Ann Arbor, Michigan

${ }^{3}$ Institute for Health Policy \& Innovation, University of Michigan, Ann Arbor, Michigan

${ }^{4}$ Department of Pediatrics and Communicable Diseases and Department of Internal Medicine, University of Michigan Health System, Ann Arbor, Michigan

${ }^{5}$ Gerald R. Ford School of Public Policy, University of Michigan, Ann Arbor, Michigan

\begin{abstract}
PURPOSE Under health care reform, states will have the opportunity to expand Medicaid to millions of uninsured US adults. Information regarding this population is vital to physicians as they prepare for more patients with coverage. Our objective was to describe demographic and health characteristics of potentially eligible Medicaid beneficiaries.
\end{abstract}

METHODS We performed a cross-sectional study using data from the National Health and Nutrition Examination Survey (2007-2010) to identify and compare adult US citizens potentially eligible for Medicaid under provisions of the Patient Protection and Affordable Care Act (ACA) with current adult Medicaid beneficiaries. We compared demographic characteristics (age, sex, race/ethnicity, education) and health measures (self-reported health status; measured body mass index, hemoglobin $\mathrm{A}_{1 \mathrm{c}}$ level, systolic and diastolic blood pressure, depression screen [9-item Patient Health Questionnaire], tobacco smoking, and alcohol use).

RESULTS Analyses were based on an estimated 13.8 million current adult nonelderly Medicaid beneficiaries and 13.6 million nonelderly adults potentially eligible for Medicaid. Potentially eligible individuals are expected to be more likely male (49.2\% potentially eligible vs $33.3 \%$ current beneficiaries; $P<.001)$, to be more likely white and less likely black (58.8\% white, $20.0 \%$ black vs $49.9 \%$ white, $25.2 \%$ black; $P=.02$ ), and to be statistically indistinguishable in terms of educational attainment. Overall, potentially eligible adults are expected to have better health status (34.8\% "excellent" or "very good," 40.4\% "good") than current beneficiaries (33.5\% "excellent" or "very good," 31.6\% "good"; $P<.001)$. The proportions obese (34.5\% vs $42.9 \%$; $P=.008$ ) and with depression $(15.5 \%$ vs $22.3 \%$; $P=.003$ ) among potentially eligible individuals are significantly lower than those for current beneficiaries, while there are no significant differences in the expected prevalence of diabetes or hypertension. Current tobacco smoking $(49.2 \%$ vs $38.0 \% ; P=.002)$, and moderate and heavier alcohol use ( $21.6 \%$ vs $16.0 \%$ and $16.5 \%$ vs $9.8 \% ; P<.001$, respectively) are more common among the potentially eligible population than among current beneficiaries.

CONCLUSIONS Under the ACA, physicians can anticipate a potentially eligible Medicaid population with equal if not better current health status and lower prevalence of obesity and depression than current Medicaid beneficiaries. Federal Medicaid expenditures for newly covered beneficiaries therefore may not be as high as anticipated in the short term. Given the higher prevalence of tobacco smoking and alcohol use, however, broad enrollment and engagement of this potentially eligible population is needed to address their higher prevalence of modifiable risk factors for future chronic disease.

Ann Fam Med 2013;406-411. doi:10.1370/afm.1553.

\section{INTRODUCTION}

\section{CORRESPONDING AUTHOR}

Tammy Chang, MD, MPH, MS 1018 Fuller St

Ann Arbor, MI 48104-1213

tachang@med.umich.edu

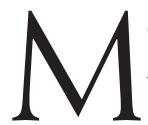

edicaid currently provides coverage for more than 50 million Americans, including more than 20 million nonelderly adults. ${ }^{1}$ Under the Patient Protection and Affordable Care Act (ACA) enacted in 2010, states will have federal support beginning in 2014 to 
expand their Medicaid programs to include all adults living at up to $138 \%$ of the federal poverty level. If implemented by states as now expected by the Congressional Budget Office after the Supreme Court ruling regarding the ACA in June 2012, Medicaid expansion is projected to add more than 10 million individuals to the Medicaid population. ${ }^{2}$

Specific income-related provisions of the ACA related to Medicaid expansion make it possible to examine national data to help clinicians and health systems anticipate patterns of new patient care beginning in 2014. Policy briefs, gray literature published by several organizations, and lay media articles have used past cohorts of nationally representative databases to anticipate characteristics of the potentially eligible with mixed findings; none have included objective health measures. Some analysts report that the uninsured low-income population is less healthy than the current Medicaid-enrolled and privately insured populations, whereas others find that the newly eligible for Medicaid and current Medicaid populations are not likely to be markedly different. ${ }^{3-8}$ Most nationally representative data sets use self-reported health measures. To our knowledge, there are no peer-reviewed reports in the medical literature using objective measures of health data (ie, measured anthropometrics, measured blood pressure readings, serum levels of various indicators) to compare the health status of the potentially eligible Medicaid population with that of current adult Medicaid beneficiaries.

The objective of this study was to use the latest nationally representative data to examine the characteristics of individuals potentially eligible for Medicaid under ACA-related coverage expansion, and compare them with those of current Medicaid beneficiaries.

\section{METHODS}

The National Health and Nutrition Examination Survey (NHANES) is a nationally representative, crosssectional survey designed to assess the health and nutritional status of the US civilian, noninstitutionalized population, used widely to assess key measures of US population health. ${ }^{9-11}$ NHANES data are released in 2-year cycles. NHANES data collection includes a personal interview in the household and a detailed physical examination and broadly used clinical laboratory tests in a mobile examination center. Additional information regarding the survey design, questionnaires, and laboratory methods is available online. ${ }^{12}$

To describe the potentially eligible Medicaid population (hereafter "potentially eligible"), we analyzed data from the most recent 2-year cycles (2007-2008 and 2009-2010). Examination survey response rates for these cycles ranged from $69 \%$ to $87 \%$. During 2007 2010, a total of 9,051 adults aged 19 to 64 years participated in the demographic questionnaire and mobile examination center examination.

This study sample was restricted to US citizens who reported (at the time of the survey) having Medicaid coverage, having a state-sponsored health plan, or having no coverage with a "ratio of family income to poverty" level of less than 1.38 (the threshold specified for expanded Medicaid coverage in the ACA). These criteria yielded an analytic sample of 1,943 adults.

For each participant, the survey team collected self-reported demographic data (citizenship status, insurance type [including none], age, sex, race/ ethnicity [non-Hispanic white, non-Hispanic black, Mexican-American, and other including multiracial], education [less than high school graduate, high school graduate/general equivalency diploma, some college and above]), and measured body mass index (BMI), measured hemoglobin $A_{1 c}$ level, and measured systolic and diastolic blood pressure. In addition, respondents indicated their self-reported health status on a 5-point scale ("excellent," "very good," "good," "fair," "poor"), tobacco smoking status, and alcohol use, and completed a validated depression screen, the 9-item Patient Health Questionnaire (PHQ-9).

We computed descriptive statistics to compare percent distribution, mean of the variables (using the Student $t$ test for continuous variables and the $\chi^{2}$ test for categorical variables), or both. Weight was classified using BMI as normal $\left(18.5-24.9 \mathrm{~kg} / \mathrm{m}^{2}\right)$, overweight $\left(25.0-29.9 \mathrm{~kg} / \mathrm{m}^{2}\right)$, or obese $\left(\geq 30 \mathrm{~kg} / \mathrm{m}^{2}\right)$. The criterion for diabetes was a hemoglobin $\mathrm{A}_{\mathrm{cc}}$ concentration of $6.5 \%$ or greater. ${ }^{13}$ Blood pressure values were the average of 3 readings taken consecutively after 5 minutes of rest; criteria for hypertension were mean systolic blood pressure of at least $140 \mathrm{~mm} \mathrm{Hg}$ or diastolic blood pressure of at least $90 \mathrm{~mm} \mathrm{Hg.}{ }^{14}$ Tobacco smoking status was specified by the following categories: never smoker (never smoked a cigarette or smoked $<100$ cigarettes in their lifetime), former smoker (smoked $\geq 100$ cigarettes in their lifetime but does not currently smoke), and current smoker (smoked $\geq 100$ cigarettes in their lifetime and currently smokes every day or some days). ${ }^{15}$ Alcohol use was defined by the following categories: nondrinker ( $<12$ drinks in lifetime or $\geq 12$ drinks in lifetime and none in the past year), light drinker (average of $\leq 3$ drinks per week), moderate drinker (average of $>3$ drinks and $\leq 14$ drinks per week if male, or $>3$ drinks and $\leq 7$ drinks per week if female), and heavier drinker (average of $>14$ drinks per week if male or an average of $>7$ drinks per week if female). ${ }^{16,17}$ Depression was defined as a PHQ-9 score of 10 or higher, a well validated and commonly used score to define this outcome. ${ }^{18}$ 
To account for the complex, multistage probability survey design, we conducted analyses applying sampling weights to permit national inferences, using STATA (version 12; Stata Corp). Results are presented as percentages or means as appropriate. Statistical significance was defined as a 2-tailed $\alpha$ less than .05. All findings are presented using weighted data, except where otherwise indicated.

\section{RESULTS}

The estimated number of adult nonelderly Medicaid beneficiaries at the time of the survey was 13.8 million, while the estimated number of nonelderly adults potentially eligible for Medicaid was 13.6 million (Table 1).

We found significant differences in demographic characteristics related to expanded Medicaid eligibility under the ACA. Potentially eligible individuals are expected to be significantly more likely male than current Medicaid beneficiaries, and more likely white and less likely black. There was no significant difference in educational attainment between the 2 groups.

Potentially eligible and current Medicaid beneficiaries also differ in expected health indicators (Table 2). Overall, potentially eligible adults report significantly better health status than current beneficiaries. In addition, potentially eligible adults are significantly less likely to be obese or have depression. There was no difference in prevalence of diabetes or hypertension between the potentially eligible individuals and current Medicaid beneficiaries. On the other hand, significantly higher pro- portions of potentially eligible individuals report current tobacco smoking and moderate or heavier alcohol use.

\section{DISCUSSION}

Our findings, based on the most recently available, nationally representative objective health measures, indicate that the potentially eligible Medicaid population under ACA-financed Medicaid expansion is at present similarly healthy as - if not healthier than - the current Medicaid population. The exception to this general theme is that tobacco smoking and alcohol use patterns are higher for potential Medicaid enrollees than for current Medicaid beneficiaries. These findings have 3 key implications for policy and practice.

First, federal Medicaid expenditures for newly covered beneficiaries may not be as high as projected by the Congressional Budget Office in the short term, thereby potentially reducing spending anticipated with implementation of the ACA. ${ }^{2}$ Second, physicians who have been reluctant to accept Medicaid as a payer because of a perceived imbalance between the typical complexity of illness for current Medicaid beneficiaries and Medicaid reimbursement may be encouraged by these findings to start accepting Medicaid patients, particularly in light of provisions within the ACA to increase Medicaid payment rates for certain primary care services to the level of Medicare. ${ }^{19-23}$ Third, active outreach and engagement of the potentially eligible population will be vital, as there is potential to improve their modifiable risk factors for future chronic disease.

Table 1. Demographic Characteristics of Adults Aged 19 to 64 Years, United States, National Health and Nutrition Examination Survey, 2007-2010

\begin{tabular}{|c|c|c|c|c|}
\hline \multirow[b]{2}{*}{ Characteristic } & \multirow{2}{*}{$\begin{array}{l}\text { Current Medicaid } \\
\text { Beneficiaries }\end{array}$} & \multirow{2}{*}{$\begin{array}{l}\text { Potentially Eligible for } \\
\text { Medicaid Under ACA }\end{array}$} & \multicolumn{2}{|c|}{$P$ Value } \\
\hline & & & $t$ Test & $\chi^{2}$ Test \\
\hline Mean age, y $(95 \% \mathrm{Cl})$ & $38.7(37.4-40.1)$ & $36.3(35.2-37.4)$ & .002 & - \\
\hline \multicolumn{3}{|l|}{ Sex, \% (95\% Cl) } & - & $<.001$ \\
\hline Male & $33.3(30.1-36.6)$ & $49.2(46.0-52.4)$ & & \\
\hline Female & $66.7(63.4-69.9)$ & $50.8(47.6-54.0)$ & & \\
\hline \multicolumn{3}{|l|}{ Race/ethnicity, \% (95\% Cl) } & - & .02 \\
\hline Non-Hispanic white & $49.9(39.8-60.1)$ & $58.8(48.7-68.2)$ & & \\
\hline Non-Hispanic black & $25.2(19.0-32.7)$ & $20.0(15.3-25.6)$ & & \\
\hline Mexican American & $9.8(7.3-13.1)$ & $11.7(6.2-21.0)$ & & \\
\hline Other & $15.0(11.0-20.1)$ & $9.6(6.6-13.8)$ & & \\
\hline \multicolumn{3}{|l|}{ Education, \% (95\% Cl) } & - & .48 \\
\hline Less than high school graduate & $35.9(31.6-40.5)$ & $35.3(29.7-41.5)$ & & \\
\hline High school graduate or GED & $28.1(24.3-32.2)$ & $31.4(28.2-34.7)$ & & \\
\hline Some college and above & $36.0(31.2-41.1)$ & $33.3(28.5-38.4)$ & & \\
\hline \multicolumn{5}{|c|}{ ACA = Patient Protection and Affordable Care Act; GED = general equivalency diploma. } \\
\hline \multicolumn{5}{|c|}{$\begin{array}{l}\text { Notes: For current Medicaid beneficiaries, unweighted } n=991 \text { and weighted } N=13.8 \text { million; for newly eligible for Medicaid, unweighted } n=952 \text { and weighted } \\
N=13.6 \text { million. Sum of percentages in each group may not equal } 100 \text { because of rounding. }\end{array}$} \\
\hline \multicolumn{5}{|c|}{ a A US citizen with "no insurance" at the time of survey interview and a "poverty-to-income ratio" of 1.38 or less. } \\
\hline
\end{tabular}


Table 2. Health Measures of Adults Aged 19 to 64 Years, United States, National Health and Nutrition Examination Survey, 2007-2010

\begin{tabular}{|c|c|c|c|}
\hline Measure & $\begin{array}{l}\text { Current Medicaid } \\
\text { Beneficiaries } \\
\%(95 \% \mathrm{Cl})\end{array}$ & $\begin{array}{l}\text { Potentially Eligible for } \\
\text { Medicaid Under ACA } \text { AC }^{\text {a }} \\
\qquad \%(95 \% \mathrm{CI})\end{array}$ & P Value ${ }^{b}$ \\
\hline Health status & & & $<.001$ \\
\hline Excellent/very good & $33.5(28.8-38.6)$ & $34.8(30.6-39.3)$ & \\
\hline Good & $31.6(28.6-34.7)$ & $40.4(36.5-44.3)$ & \\
\hline Fair/poor & $35.0(30.6-39.5)$ & $24.8(22.3-27.5)$ & \\
\hline Body mass index & & & .008 \\
\hline Normal weight & $24.6(21.3-28.2)$ & $31.5(28.1-35.1)$ & \\
\hline Overweight & $29.9(25.7-34.5)$ & $29.9(27.2-32.8)$ & \\
\hline Obese & $42.9(37.8-48.3)$ & $34.5(30.8-38.4)$ & \\
\hline Diabetes $^{d}$ & $7.5(5.7-9.9)$ & $5.2(3.6-7.4)$ & .094 \\
\hline Hypertension ${ }^{e}$ & $9.9(7.9-12.4)$ & $12.3(10.2-14.7)$ & .15 \\
\hline Depression ${ }^{f}$ & $22.3(19.5-25.3)$ & $15.5(12.8-18.8)$ & .003 \\
\hline Smoking ${ }^{g}$ & & & .002 \\
\hline Never smoker & $44.8(38.9-50.8)$ & $37.1(32.6-42.0)$ & \\
\hline Former smoker & $17.3(13.6-21.7)$ & $13.7(11.0-16.9)$ & \\
\hline Current smoker & $38.0(33.0-43.3)$ & $49.2(43.8-54.6)$ & \\
\hline Alcohol use ${ }^{h}$ & & & $<.001$ \\
\hline Nondrinker & $17.7(14.0-22.0)$ & $12.7(9.9-16.0)$ & \\
\hline Light drinker & $56.5(50.5-62.2)$ & $49.2(45.2-53.2)$ & \\
\hline Moderate drinker & $16.0(12.7-20.1)$ & $21.6(17.5-26.5)$ & \\
\hline Heavier drinker & $9.8(8.0-12.0)$ & $16.5(12.9-21.0)$ & \\
\hline \multicolumn{4}{|c|}{ ACA = Patient Protection and Affordable Care Act. } \\
\hline \multicolumn{4}{|c|}{$\begin{array}{l}\text { c Underweight omitted }\left(<5 \% \text { of population). Body mass index was classified as normal }\left(18.5-24.9 \mathrm{~kg} / \mathrm{m}^{2}\right) \text {, }\right. \\
\text { overweight }\left(25.0-29.9 \mathrm{~kg} / \mathrm{m}^{2}\right) \text {, or obese }\left(\geq 30 \mathrm{~kg} / \mathrm{m}^{2}\right)\end{array}$} \\
\hline \multicolumn{4}{|c|}{${ }^{d} A$ hemoglobin $A_{1 c}$ level of $6.5 \%$ or greater. } \\
\hline \multicolumn{4}{|c|}{$\begin{array}{l}\text { e Systolic blood pressure } 140 \mathrm{~mm} \mathrm{Hg} \text { or greater or diastolic blood pressure } 90 \mathrm{~mm} \mathrm{Hg} \text { or greater. Blood } \\
\text { pressure averaged over } 3 \text { consecutive measurements after } 5 \text {-minute rest. }\end{array}$} \\
\hline \multicolumn{4}{|c|}{ fA score of greater than 10 on 9-item Patient Health Questionnaire screen. } \\
\hline \multicolumn{4}{|c|}{$\begin{array}{l}\text { g Never smoker defined as smoking fewer than } 100 \text { cigarettes in lifetime. Former smoker defined as smok- } \\
\text { ing more than } 100 \text { cigarettes in lifetime and not currently smoking. Current smoker defined as smoking } \\
\text { more than } 100 \text { cigarettes in lifetime and currently smoking daily or some days. }\end{array}$} \\
\hline \multicolumn{4}{|c|}{$\begin{array}{l}\text { h Nondrinkers had no drinks in the past year, including former drinkers and lifetime abstainers. Light drink- } \\
\text { ers had an average of } 3 \text { drinks or less per week. Moderate drinkers had an average of } 4 \text { to } 14 \text { drinks per } \\
\text { week if male and } 4 \text { to } 7 \text { drinks per week if female. Heavier drinkers had an average of more than } 14 \text { drinks } \\
\text { per week if male or an average of more than } 7 \text { drinks per week if female. }\end{array}$} \\
\hline
\end{tabular}

rently lower chronic disease burden may be explained by the fact that the potentially eligible-despite being uninsured-are drawn from a population with higher income than current Medicaid beneficiaries and are therefore likely healthier. ${ }^{24}$ The greater prevalence of moderate to heavier drinking with higher incomes is also consistent with known trends. ${ }^{15}$ These findings support a need for emphasis on preventive health care in the potentially eligible population, even though they currently have a lower chronic disease burden.

Our study also offers insights about the demographic composition of the potentially eligible population. We find that they are expected to be younger, with no difference in educational attainment between the potentially eligible population and the current Medicaid population. This finding may be explained by new eligibility for young adults who exceed the ACA-based age limit (26 years) for coverage on their parents' health plans or are entering the lowwage workforce and may not have other access to health insurance. In addition, this potential population of Medicaid beneficiaries will include a higher proportion of male individuals than the current Medicaid population; pre-ACA Medicaid eligibility has focused predominantly on women and their children, excluding many childless low-income men. It
Our findings are consistent with a study by the Urban Institute using other national data that found that both currently uninsured and privately insured adults with incomes below $138 \%$ of the federal poverty level are healthier on average than both the nondisabled and the disabled adults who are currently enrolled in Medicaid. ${ }^{5}$ Using NHANES data, our study builds on this prior work by using measured, objective anthropometric and serum laboratory data from its respondents, rather than only self-reported data regarding disease states. Taken together, these analyses indicate that the potentially eligible appear to have a somewhat lower chronic disease burden, though greater prevalence of poor health behaviors such as tobacco smoking and heavy alcohol use. Their cur- will be instructive to monitor early patterns of health care use among newly Medicaid enrolled individuals as young adult men have typically been infrequent users of routine medical care.

Although our analysis has several strengths, our findings must be interpreted with certain caveats. First, the NHANES is a cross-sectional study and can be used descriptively, but not to show predictive or temporal relationships because sequential samples are drawn separately. ${ }^{12}$ Second, the health status of the potentially eligible Medicaid beneficiaries will be greatly influenced by the level of participation by states and individuals under the $\mathrm{ACA}_{i}$ participation by states in ACA-financed Medicaid expansion (completely, partly, or not at all ${ }^{2}$ ) is not certain at this time. 
Our analysis presents outcomes as if all states and eligible individuals will participate fully in the Medicaid expansion. ${ }^{25,26}$ To the extent that states and individuals do not participate, the potentially eligible and current beneficiaries may not differ in the ways we report. On the basis of latest projections at the time of writing, 18 states have governors who do not support Medicaid expansion. ${ }^{27}$ Several of these states (Mississippi, Alabama, Louisiana) have some of the poorest population health measures in the country. ${ }^{28} \mathrm{As}$ a result, it is possible our analysis may underestimate the health of the states that plan to participate in the expansion because those states are healthier at baseline. Conversely, adverse selection is likely to result in the enrollment of the sickest individuals in each state (at least initially), which emphasizes the importance of outreach efforts to enroll healthier individuals to achieve lower average costs. ${ }^{5}$ Finally, our potentially eligible sample also contains individuals who may have previously been eligible for Medicaid or had access to private health insurance, but were healthy enough to choose to not enroll, which could make our potentially eligible sample appear healthier. Because of the individual mandate for health insurance coverage under the ACA, however, the distinction between previously and newly eligible Medicaid patients will not be relevant to physicians who would consider both new patients. Importantly, because the enforcement of mandatory health insurance enrollment is expected to occur through the tax system, there may be a delay in widespread enrollment.

These limitations notwithstanding, our analysis indicates that millions of nonelderly adults eligible for Medicaid under provisions of the ACA will differ in key demographic and health characteristics from current Medicaid beneficiaries. Physicians and facilities that currently care for Medicaid patients will likely care for this potentially eligible population and will have the opportunity to reduce the prevalence of poor health behaviors, while physician practices that do not accept Medicaid patients may be encouraged to open their doors to an eligible population that is currently equally healthy if not healthier. Broader participation by physicians in Medicaid may be a critical element of ensuring adequate access to care with expanded Medicaid under the ACA.

To read or post commentaries in response to this article, see it online at http://www.annfammed.org/content/11/5/406.

Key words: Medicaid; health care reform; uninsured; health status; diabetes; hypertension; obesity; BMI; depression; smoking; tobacco; alcohol; chronic disease

Submitted December 13, 2012; submitted, revised, April 17, 2013; accepted May 21, 2013.
Funding support: Tammy Chang receives salary support from the Robert Wood Johnson Foundation Clinical Scholars Program.

Prior presentations: North American Primary Care Research Group Annual Meeting, December 1-5, 2012, New Orleans, Louisiana.

Acknowledgments: Dr Chang would like to acknowledge Andrew Bazemore and the Robert Graham Center for their support and mentorship on this project.

\section{References}

1. DeNavas-Walt C, Proctor BD, Smith JC. Income, poverty, and health insurance coverage in the United States: 2011. Issued September 2012 by the US Census Bureau. http://www.census.gov/ prod/2012pubs/p60-243.pdf. Accessed Oct 1, 2012.

2. Congressional Budget Office. Estimates for the insurance coverage provisions of the Affordable Care Act updated for the recent Supreme Court decision. July 2012. http://www.cbo.gov/sites/ default/files/cbofiles/attachments/43472-07-24-2012-CoverageEstimates.pdf. Accessed Oct 1, 2012.

3. Roehrig C, Turner A. Health Status of the Uninsured and Implications for Physician Requirements Under the Affordable Care Act. Washington, DC: Altarum Institute; 2011.

4. Pourat N, Martinez AE, Kominski GF. Californians newly eligible for Medi-Cal under health care reform. Policy Brief UCLA Cent Health Policy Res. May 2011. Report PB2011-4:1-7.

5. Holahan J, Kenney G, Pelletier J. The Health Status of New Medicaid Enrollees Under Health Reform. Timely Analysis of Immediate Health Policy Issues. Washington, DC: Urban Institute; 2010.

6. CaliforniaHealthline.com. Newly Eligible Medicaid Enrollees Less Healthy Than Current Enrollees. August 2011. http://www. californiahealthline.org/articles/2011/8/10/newly-eligible-medicaid-enrolleesless-healthy-than-current-enrollees.aspx. Accessed Sep 17, 2012.

7. InsideHealthPolicy.com. Insurers react as Avalere finds newly eligible Medicaid beneficiaries in poorer health. August 2011. http:// insidehealthpolicy.com/Inside-Health-General/Public-Content/ insurers-react-as-avalere-finds-newly-eligible-medicaid-beneficiariesin-poorer-health/menu-id-869.html. Accessed Sep 17, 2012.

8. Natoli C, Cheh V, Verghese S. Who Will Enroll in Medicaid in 2014? Lessons from Section 1115 Medicaid Waivers. Baltimore, MD: Centers for Medicare \& Medicaid Services. Medicaid Policy Brief. May 2011(Brief 1):1-6.

9. Yang Q, Cogswell ME, Flanders WD, et al. Trends in cardiovascular health metrics and associations with all-cause and CVD mortality among US adults. JAMA. 2012;307(12):1273-1283.

10. Ogden CL, Carroll MD, Kit BK, Flegal KM. Prevalence of obesity and trends in body mass index among US children and adolescents, 1999-2010. JAMA. 2012;307(5):483-490.

11. Wilper AP, Woolhandler S, Lasser KE, McCormick D, Bor DH, Himmelstein DU. A national study of chronic disease prevalence and access to care in uninsured U.S. adults. Ann Intern Med. 2008;149 (3):170-176.

12. Centers for Disease Control and Prevention. National Health and Nutrition Examination Survey. http://www.cdc.gov/nchs/nhanes. htm. Accessed Sep 17, 2012.

13. American Diabetes Association. Standards of medical care in diabetes-2012. Diabetes Care. 2012;35(Suppl 1):S11-S63.

14. Chobanian AV, Bakris GL, Black HR, et al; Joint National Committee on Prevention, Detection, Evaluation, and Treatment of High Blood Pressure. National Heart, Lung, and Blood Institute; National High Blood Pressure Education Program Coordinating Committee. Seventh report of the Joint National Committee on Prevention, Detection, Evaluation, and Treatment of High Blood Pressure. Hypertension. 2003;42(6):1206-1252. 
15. Fryar CD, Hirsch R, Porter KS, et al. Smoking and alcohol behaviors reported by adults: United States, 1999-2002. Natl Health Stat Report. 2009;20(15):1-23.

16. US Department of Health and Human Services. Behavioral Risk Factor Surveillance System. http://www.cdc.gov/brfss/index.htm. Accessed Apr 12, 2013.

17. US Department of Health and Human Services. Helping Patients Who Drink Too Much: A Clinician's Guide, 2005 edition. http://pubs. niaaa.nih.gov/publications/Practitioner/CliniciansGuide2005/guide. pdf. Accessed Apr 12, 2013.

18. Kroenke K, Spitzer RL, Williams JB. The PHQ-9: validity of a brief depression severity measure. J Gen Intern Med. 2001;16(9):606-613.

19. Decker SL. In 2011 nearly one-third of physicians said they would not accept new Medicaid patients, but rising fees may help. Health Aff (Millwood). 2012;31(8):1673-1679.

20. Sommers AS, Boukus ER, Carrier E. Dispelling myths about emergency department use: majority of Medicaid visits are for urgent or more serious symptoms. Res Brief. 2012(23):1-10, 11-13.

21. Medicaid.gov. Provider Payments under Affordable Care Act. http://www.medicaid.gov/AffordableCareAct/Provisions/ProviderPayments.html. Accessed Oct 31, 2012.
22. Bindman AB, Yoon J, Grumbach K. Trends in physician participation in Medicaid. The California experience. J Ambul Care Manage. 2003; 26(4):334-343.

23. Perloff JD, Kletke P, Fossett JW. Which physicians limit their Medicaid participation, and why. Health Serv Res. 1995;30(1):7-26.

24. Ettner SL. New evidence on the relationship between income and health. J Health Econ. 1996;15(1):67-85.

25. Gostin LO. The Supreme Court's historic ruling on the Affordable Care Act: economic sustainability and universal coverage. JAMA. 2012;308(6):571-572.

26. Jost TS, Rosenbaum S. The Supreme Court and the future of Medicaid. N Engl J Med. 2012;367(11):983-985.

27. The Advisory Board Company. Where each state stands on ACA's Medicaid expansion. March 27, 2013. http://www.advisory.com/ Daily-briefing/2012/11/09/MedicaidMap\#lightbox/1/. Accessed Apr 12, 2013.

28. Kaiser Family Foundation. Health Status by State. http://www.statehealthfacts.org/. Accessed Apr 12, 2013.

\section{CHANGE-OF-ADDRESS FORM FAMNILY MEDICINE}

Please complete this form and mail to the following address or fax to Annals Circulation at 913-906-6080:

Annals of Family Medicine, Circulation Department, 11400 Tomahawk Creek Pkwy, Leawood, KS 66211-2680

Check if member of sponsoring organization:

$\begin{array}{ll}\square \text { AAFP } & \square \text { ABFM } \square \text { STFM } \square \text { ADFM } \\ \square \text { AFMRD } & \square \text { NAPCRG } \square \text { CFPC }\end{array}$

ID number from label on your journal cover

OLD Information (Please print.)

\begin{tabular}{ll}
\hline Name & \\
\hline Company (if applicable) & \\
\hline Address (Street plus Apt or Ste) & State \\
\hline City & Postal Code (9-digit ZIP for US) \\
\hline Country & Fax \\
\hline Telephone & \\
\hline E-Mail
\end{tabular}

NEW Information (Please print.)

\begin{tabular}{ll}
\hline Name \\
\hline Company (if applicable) & \\
\hline Address (Street plus Apt or Ste) & \\
\hline City & Postal Code (9-digit ZIP for US) \\
\hline Country & Fax \\
\hline Telephone & \\
\hline E-Mail &
\end{tabular}

